\title{
ETIOLOGIA DO DECLÍNIO DE MANGOSTANZEIROS NO SUL DA BAHIA ${ }^{1}$
}

\author{
EDUARDO CÉSAR ARAÚJO PAIM ${ }^{2}$, ARLETE JOSÉ DA SILVEIRA ${ }^{3}$ \\ JOSÉ LUIZ BEZERRA ${ }^{4}$, EDNA DORA MARTINS NEWMAN LUZ ${ }^{5}$ \\ CÉLIO KERSUL DO SACRAMENTO 6
}

RESUMO - O declínio do mangostanzeiro (Garcinia mangostana L.) no litoral sul do Estado da Bahia é hoje o principal problema da cultura, sendo caracterizado por sintomas de murcha, amarelecimento, seca e queda de folhas. Este trabalho teve como objetivo acompanhar a evolução da sintomatologia da doença, isolar e identificar os potenciais patógenos causadores do declínio do mangostanzeiro. A doença começa com a necrose das radículas, a qual atinge as raízes secundárias, primárias e progride até à base do tronco que desenvolve lesões necróticas extensas. Os sintomas secundários são clorose, murcha e queda das folhas. Das amostras de tecidos lesionados de plantas doentes levadas ao laboratório, foram isolados e identificados os seguintes fungos: Lasiodiplodia theobromae, Lasiodiplodia parva, Mycoleptodiscus sp., Rhizopus sp., Stilbella sp., Trichoderma spp. e Aspergillus sp. Apenas L. theobromae e L. parva foram patogênicas a fragmentos de raízes e caules de mangostanzeiros in vitro e a mudas de mangostanzeiros em casa de vegetação, sendo o isolado da primeira espécie o mais virulento. A taxonomia do gênero Lasiodiplodia e algumas condições que influenciam no desenvolvimento da doença no campo foram analisadas.

Termos para indexação: Garcinia mangostana, patologia de frutíferas, Lasiodiplodia spp., etiologia.

\section{ETIOLOGY OF THE DECLINE OF MANGOSTEEN IN THE SOUTHERN BAHIA}

\begin{abstract}
The decline of mangosteen (Garcinia mangostana L.) in the southern coast of the state of Bahia is today the main problem of the culture, being characterized by symptoms of wilting, yellowing, blight and defoliation. This study was aimed to follow the evolution of the symptoms of the disease, isolate and identify the possible pathogen of mangosteen decline. The disease begins in the roots and progresses toward the canopy, leading to plant death. Samples of infected tissue from diseased plants were taken to laboratory where the following fungal species were isolated and identified: Lasiodiplodia theobromae, L. parva, Mycoleptodiscus sp., Rhizopus sp., Stilbella sp., Aspergillus sp. and Trichoderma spp. Only Lasiodiplodia theobromae and L. parva were pathogenic to fragments of roots and stems in vitro and mangosteen seedlings in glass house, being the first species the more virulent. The taxonomy of the genus Lasiodiplodia and some conditions that influence the development of the disease in the field were analyzed.
\end{abstract}

Index terms: Garcinia mangostana, fruit tree pathology, Lasiodiplodia spp., etiology.

\section{INTRODUÇÃO}

O mangostão ou mangostin (Garcinia mangostana L.), fruto do mangostanzeiro, é considerado a fruta mais saborosa do trópico asiático. Pertencente à família Clusiaceae e originário da Ásia, o mangostanzeiro é de disseminação restrita, cultivado, principalmente, nas regiões tropicais da Ásia, Índia, Austrália e em alguns países da América. No Brasil, foi introduzido em 1935, no Estado da Bahia, e, em 1942, no Estado do Pará (SACRAMENTO et al., 2007), sendo cultivado hoje, além destes dois
Estados, porém, em menor escala, no Espírito Santo e em São Paulo.

Nas regiões produtoras de mangostão, têm sido relatados diversos problemas fitossanitários sem, no entanto, serem considerados impeditivos para a produção (SACRAMENTO et al., 2007). Entretanto, no litoral da região sul da Bahia, a síndrome do declínio do mangostanzeiro em plantas na fase de frutificação, tanto em plantios comerciais como em plantas isoladas, é hoje o principal problema dessa cultura. Esse tipo de problema só tem ocorrido nos plantios comerciais do sul da Bahia, não havendo

\footnotetext{
1(Trabalho 077-12). Recebido em: 31-01-2012. Aceito para publicação em: 10-08-2012.

${ }^{2}$ Eng $^{\circ}$ Agrônomo, MSc. E-mail: edcepaim@hotmail.com

${ }^{3} E^{2}{ }^{a}$ Agrônoma, DSc. Professora Plena do DCAA/UESC. Ilhéus. E-mail: arletesilveira@uesc.br

${ }^{4}$ Biólogo, PhD, Professor visitante DCAA/UESC, Ilhéus. E-mail: jlbezerra@cepec.gov.br

${ }^{5} E_{n}$ a Agrônoma, PhD. Pesquisadora, CEPEC/CEPLAC, Ilhéus. E-mail: ednadora@cepec.gov.br

${ }^{6}$ Eng $^{\text {o }}$ Agrônomo, DSc. Professor Pleno, DCAA/UESC, Ilhéus. E-mail: kersul@uesc.br
} 
relatos em outras regiões produtoras do Brasil ou do exterior.

Os sintomas do declínio do mangostanzeiro (DM) são murcha, amarelecimento, seca e queda de folhas, culminando com a morte da planta. As observações em campo têm mostrado que o declínio do mangostanzeiro está relacionado a uma patologia que se inicia nas raízes mais finas, extendendo-se para as demais, provocando o escurecimento das mesmas e levando-as ao apodrecimento e à morte. Nas raízes mais grossas, os sintomas da infecção aparecem inicialmente entre o córtex e o lenho, evoluindo para o interior desses tecidos. Os sintomas estendem-se para o tronco, ocasionando o escurecimento dos tecidos, provocando no restante da planta sintomas de murcha, amarelecimento, seca e queda de folhas. Entre um e dois meses após o aparecimento dos primeiros sintomas da doença na parte aérea, a planta é reduzida apenas a ramos secos.

Não há relatos de quando começaram os problemas de declínio de mangostanzeiros na região sul da Bahia, mas, segundo alguns produtores, as primeiras plantas morreram em 1993. Conforme os registros da Clínica Fitopatológica Waldemar Tobias Lellis, do Centro de Pesquisa do Cacau (CEPEC/ CEPLAC - Ilhéus-BA), no ano de 2001, foram enviados para exame materiais de plantas dessa fruteira com sintomas de declínio. Das amostras examinadas, foram identificados diversos fungos (BEZERRA et al., 2003).

Considerando que o mangostanzeiro é cultivado em espaçamentos de $8 \mathrm{~m}$ ou mais entre plantas, que leva mais de 10 anos para entrar em plena produção e, quando adulto, produz, em média, 600 frutos, a morte de uma planta causa grande prejuízo aos produtores.

Desse modo, o presente trabalho teve por objetivo estudar a sintomatologia e as causas do declínio do mangostanzeiro, num enfoque fitopatológico, através de coleta de informações junto aos produtores, amostragens e coleta de tecidos doentes, isolamento e identificação de patógeno(s), e testes de patogenicidade in vitro, em laboratório, e em mudas em condições de casa de vegetação.

\section{MATERIAL E MÉTODOS}

Amostras de material para estudo foram coletadas de mangostanzeiros com mais de cinco anos de plantio que apresentavam sintomas de declínio em plantios comerciais do município de Una, Bahia. Os trabalhos de isolamento, classificação e inoculação in vitro dos fungos foram conduzidos no Centro de Pesquisas do Cacau (CEPEC/CEPLAC - Ilhéus-BA).
Os registros da Clínica Fitopatológica do Centro de Pesquisas do Cacau (CEPEC/CEPLAC - Ilhéus-BA) foram consultados para verificar quais fungos foram isolados em amostras de mangostanzeiros com sintomas de declínio, enviadas para análise, no período compreendido entre 2001 e 2008.

As áreas com plantio do mangostanzeiro onde ocorre o declínio foram selecionadas por meio de consultas a produtores e a pesquisadores da CEPLAC e da UESC. Plantios comerciais, do município de Una, Bahia, com diferentes níveis de $\mathrm{DM}$, foram prospectados com o fim de se verificar diferenças nos tratos culturais e suas relações com o aparecimento da doença. Os proprietários dessas áreas informaram as épocas prováveis do aparecimento da doença, os tratos culturais aplicados, as características químicas e físicas do solo e outros dados considerados relevantes.

Foram coletadas amostras de raízes e de caules entre os meses de janeiro e julho de 2009. Em duas ocasiões, foram coletadas mudas que apresentavam manchas necróticas na epiderme do caule e nas folhas, a primeira em maio, e a segunda, em junho, em pequenos viveiros localizados em fazendas, no município de Una.

A evolução dos sintomas foi acompanhada em duas plantas com mais de cinco anos de plantio, desde os primeiros indícios da doença até a morte das plantas. Nessas plantas, também foram realizadas coletas de amostras nos meses de março, abril e maio de 2009.

As coletas foram realizadas em mangostanzeiros com sintomas de declínio após a remoção da serapilheira e escavação do solo para exposição das raízes e da base do tronco para retirada de amostras dos tecidos lesionados. Essas amostras foram colocadas em sacos de papel com identificação da origem do material.

Para isolamento e classificação dos fungos presentes nas amostras, foram retirados seis pequenos fragmentos de tecidos $(5 \times 3 \mathrm{~mm})$ da região de transição entre o tecido doente e o sadio, os quais foram desinfestados pela imersão em solução de hipoclorito de sódio a $2 \%$, durante um minuto, e lavados duas vezes em água destilada estéril, secados em papel toalha estéril e colocados em placas de Petri de vidro contendo meio BDA (Batata-Dextrose-Ágar), incubadas à temperatura ambiente $\left( \pm 27^{\circ} \mathrm{C}\right)$ sob luz fluorescente branca.

sporuladas para caracterização morfológica, mensuração e fotomicrografias das estruturas de valor taxonômico. A identificação dos fungos baseou-se na observação das características macroscópicas e microscópicas de cada um, na utilização de chaves 
de gênero e na comparação com as descrições das espécies na literatura especializada.

As culturas foram conservadas em água destilada estéril e sob óleo mineral estéril. Os fungos com potencial fitopatogênico foram mantidos em crescimento ativo através de sucessivas repicagens, em meio de BDA.

As inoculações in vitro foram feitas em folhas, secções de caules e de raízes sadios $(13$ x $10 \mathrm{~cm})$, desinfestadas e com as extremidades impermeabilizadas com cera de abelha para evitar a desidratação. Nas secções dos caules e das raízes, foram feitos cortes em bisel e, nas folhas, ferimentos quadrados ( $10 \times 10$ $\mathrm{cm}$ ), expondo-se a epiderme. Sobre cada ferimento, foi depositado um disco de $10 \mathrm{~mm}$ de diâmetro retirado da margem da colônia em BDA. Folhas e secções de caules e raízes sem ferimentos foram inoculadas igualmente. Nas testemunhas, caules, raízes e folhas, com e sem ferimentos, receberam apenas um disco de BDA estéril. O inóculo foi recoberto com um chumaço de algodão embebido em água destilada estéril, e as folhas e secções de caules e raízes, colocadas em placas de Petri (15 cm de diâmetro), contendo papel de filtro estéril umedecido, sendo incubadas por quarenta e 45 dias. Reisolamentos foram feitos a partir das lesões resultantes das inoculações.

Para teste de patogenicidade in vivo, usou-se inóculo retirado de culturas em BDA, incubadas à temperatura ambiente $\left( \pm 27^{\circ} \mathrm{C}\right)$, sob luz fluorescente branca, durante três dias. Discos com $10 \mathrm{~mm}$ de diâmetro foram inoculados em mudas de mangostanzeiro de 12 meses de idade, em sacos plásticos de $10 \mathrm{~kg}$ de capacidade. Na base do caule, numa altura de três centímetros do coleto, foi feito um corte em bisel expondo-se o xilema, formando-se um ferimento de, aproximadamente, $3 \mathrm{~cm}$ de comprimento e com largura variável em função do diâmetro do caule, sobre os quais foi depositado o inóculo. A seguir, a casca do caule foi recolocada e o local isolado com fita veda rosca. As plantas-testemunha foram inoculadas com um disco de BDA estéril. Inocularam-se 60 plantas com os dois fungos pré-selecionados in vitro, ficando 20 como testemunhas. Oito dias após a inoculação, a fita veda-rosca foi retirada para observação diária do aparecimento de lesões durante 45 dias ou até a morte das plantas. Constatada a infecção, foram retiradas amostras para se proceder ao reisolamento do fungo.

\section{RESULTADOS E DISCUSSÃO}

Nos registros da Clínica Fitopatológica do CEPEC, constam que numerosos fungos foram encontrados em mangostanzeiros com sintomas de murcha, com maior frequência $(78 \%)$ do fungo $L$. theobromae (Tabela 1).

Com base nas observações sistemáticas feitas no campo, a sintomatologia do DM ficou caracterizada pela murcha inicial das folhas dos ramos mais altos da árvore, refletindo a colonização das raízes mais finas pelo patógeno. Posteriormente, todas as folhas se tornaram murchas e amareladas, secando em seguida e caindo ao solo, ficando apenas os ramos secos. Neste estágio, o patógeno já alcançara as raízes de maior diâmetro e a base do tronco, avançando verticalmente em direção à copa. A enfermidade ocorre em plantas com mais de cinco anos, em reboleira, enfileiradas ou isoladas (Figura 1B e 1A). Os frutos, se existentes, secam e permanecem presos aos ramos. A murcha unilateral da copa ocorre quando o patógeno invade as raízes de um só lado da planta.

Foram observadas plantas com secamento da parte aérea ou mortas, com parte das raízes e da base do caule apresentando-se necrosadas. Não foi observado anelamento da base do caule. Em algumas dessas plantas, constataram-se perfurações e a presença de escolitídeos (Coleóptera: Scolytidae), que apareceram após o início dos sintomas (Figura 2A).

Os sintomas internos aparecem inicialmente entre a casca e o lenho, nas raízes de maior diâmetro e no tronco (Figura 2B), aprofundando-se no lenho e avançando no sentido ascendente. Os tecidos afetados tornam-se de cor creme-clara a castanha e depois negra, quando sobrevém a necrose. A morte da planta acontece entre dois e três meses após o aparecimento dos primeiros sintomas. Nas mudas naturalmente infectadas e apresentando manchas necróticas, não se observou a morte das mesmas.

Sintomas semelhantes foram observados por Ito et al. (2001) em nogueiras-macadâmia (Macadamia integrifolia) com necroses causadas por Lasiodiplodia theobromae e que também apresentavam perfurações causadas por escolitídeos - Coleóptera: Scolytidae.

Foram encontradas três plantas mortas devido ao ataque do fungo Rosellinia sp., agente causal comprovado de podridão de raízes em várias culturas (MARTIJN; KRAUSS, 2006). Este fungo não foi relatado ainda em mangostanzeiro. Segundo Oliveira e Luz (2005), no Brasil, R. pepo é a espécie que se tem manifestado com maior prevalência em cacaueiros, sendo que a doença causa maiores danos em plantações formadas em terrenos recémdesmatados.

Conforme relato dos agricultores, o DM está associado com períodos prolongados de seca ou de chuva; plantios em solos pouco profundos; grande produção de frutos no ano anterior; prática 
de retirar parte do solo ao redor do tronco; e aplicação de herbicidas. Apesar de esses fatores influenciarem na ocorrência de muitas fitomoléstias, não foi possível comprovar alguma correlação desses fatores com o DM. Em propriedades onde as plantas foram devidamente adubadas com fosfatos e micronutrientes e redução da adubação nitrogenada e potássica, houve menor número de casos registrados, mas não há comprovação científica dessas afirmativas.

Das amostras coletadas neste trabalho, em plantas em produção, foram isoladas e identificadas as espécies de fungos: Lasiodiplodia theobromae (Pat.) Griffon \& Maubl., 1909) e L. parva A.J.L. Philips, A. Alves \& Crous, Mycoleptodiscus sp., Rhizopus sp., Stilbella sp., Trichoderma spp. e Aspergillus sp. Em mudas coletadas em viveiro $L a-$ siodiplodia theobromae foi a única espécie isolada, entretanto o gênero Lasiodiplodia foi isolado em todas as seis coletas.

As duas espécies de Lasiodiplodia possuem crescimentos distintos. São muito semelhantes quanto às estruturas reprodutivas e conídios, embora esses últimos sejam mais truncados em $L$. theobromae do que em $L$. parva. Ambas apresentam conídios hialinos quando imaturos e 1-septados, longitudinalmente estriados à maturidade, e picnídios típicos do gênero. $\mathrm{O}$ crescimento de $L$. theobromae em meio de cultura $\mathrm{BDA}$ é mais rápido do que o de $L$. parva (Tabela 2). Além disso, à temperatura de $35^{\circ} \mathrm{C}, L$. parva apresentou coloração rosa-escura (Figura 3A e 3B), e L. theobromae, clara (até o sexto dia), e depois cinza ou negra (nas culturas mais velhas) em BDA (Figura 3C e 3D), atendendo a um critério importante de separação das duas espécies (ALVES; PHILLIPS, 2008).

A análise dos dados quanto à frequência de ocorrência (Tabela 4), segundo Dajoz (1983), revelou que, em todas as coletas, o gênero Lasiodiplodia foi muito frequente $(83,33 \%)$, o gênero Trichoderma foi pouco frequente $(10,42 \%)$ e os demais gêneros ocorreram esporadicamente (Mycoleptodiscus, 8,33\%; Aspergillus, 4,86\%; Stilbella, 4,17\%; e Rhizopus, 2,08\%).

A análise da constância dos isolados (Tabela 5) mostrou que os gêneros Lasiodiplodia e Aspergillus foram constantes nas coletas $(100 \%$ e $66,67 \%$, respectivamente), os gêneros Stilbella e Trichoderma acessórios (33,33\% e 50\%, respectivamente) e os gêneros Mycoleptodiscus e Rhizopus acidentais (16,67\% cada um), de acordo com Cavalcanti e Mobim (2004).

Esses resultados demonstram que não houve similaridade entre as coletas.
Nas inoculações realizadas in vitro, em folhas e em fragmentos de caule (Figura 4D) e raiz (Figura 4C) de mangostanzeiro, apenas os fungos $L$. theobromae e L. parva foram capazes de infectar e colonizar o hospedeiro nas amostras com ferimento, não ocorrendo infecção em folhas (Tabela 3). Após 14 dias da inoculação, foram observados os mesmos sintomas internos presentes nas infecções naturais. Lasiodiplodia theobromae infectou $100 \%$ das amostras e $L$. parva $70 \%$ das amostras de caule e $80 \%$ das amostras de raiz.

Lasiodiplodia theobromae e L. parva provocaram infecção em todas as mudas de mangostanzeiro inoculadas. Entretanto, no período observado (45 dias), das 20 mudas infectadas por $L$. theobromae, 17 desenvolveram lesões extensas $( \pm 12 \mathrm{~cm}$ de comprimento), enquanto das 20 mudas infectadas por Lasiodiplodia parva, apenas 13 desenvolveram lesões extensas (Figura 5B e 5D). Vinte e dois dias após a inoculação, morreram cinco mudas. Quarenta e cinco dias após a inoculação com o gênero Lasiodiplodia, das quarenta mudas inoculadas, apenas duas mudas inoculadas com $L$. theobromae e cinco mudas inoculadas com $L$. parva permaneceram vivas.

$\mathrm{O}$ fungo $L$. theobromae é um patógeno que causa danos em espécies como cacaueiro (FUKUDA et al., 2008), cajueiro (CARDOSO et al., 2009), pinhão-manso (PEREIRA et al., 2009) e mangueira (LINS et al., 2010). No mangostanzeiro, o ataque de L. theobromae parece estar relacionado com o estresse da planta em determinada fase do seu desenvolvimento, o qual pode estar associado a um fator ou a um conjunto de fatores característicos de uma dada área, incluindo aí as práticas culturais utilizadas. Cardoso et al. (2009) descrevem detalhadamente a resinose do cajueiro causada por $L$. theobromae, principal doença dessa cultura no semiárido nordestino que ocorre comumente em plantas submetidas a estresse, confirmando as presentes observações sobre o DM.

Os resultados obtidos nas inoculações artificiais realizadas in vitro corresponderam às inoculações de mudas de mangostanzeiros em casa de vegetação.

Resultado semelhante foi encontrado por Luz e Silva (2001) trabalhando com discos de folhas e frutos destacados de cacau inoculados com Phytophthora spp. e Luz (1989) com folhas, frutos, raízes destacadas e plântulas de cacaueiro inoculadas com quatro espécies de Phytophthora patogênicas ao cacaueiro.

TABELA 2 - Principais diferenças entre as espécies identificadas do gênero Lasiodiplodia patogênicas ao mangostanzeiro.

\begin{tabular}{cc}
\hline Gênero & Conídios \\
\cline { 2 - 2 } & Tamanho $(\mu \mathrm{m}) *$ \\
\hline
\end{tabular}


TABELA 1- Relação dos gêneros de fungos isolados a partir de 34 amostras de material vegetal de mangostanzeiros com alguma patologia (sintomas) enviada à Clínica Fitopatológica da CEPLAC por produtores de diversas localidades do sul da Bahia, no período de junho de 2001 a março de 2008.

\begin{tabular}{lccc}
\hline Gênero isolado & $\mathrm{n}^{\text {o }}$ de ocorrências & Municípios em que ocorreu & Frequência (\%) \\
\hline Aspergillus & 1 & Una & 3,85 \\
Beltrania & 1 & Una & 3,85 \\
Beltraniopsis & 1 & Una & 3,85 \\
Cladobotryum & 1 & Una & 3,85 \\
Clonostachys & 2 & Taperoá, Una & 7,69 \\
Cylindrocarpon & 1 & Ituberá & 3,85 \\
Cylindrocladiella & 2 & Una & 7,69 \\
Cylindrocladium & 2 & Una & 7,69 \\
Cytospora & 1 & Ituberá & 3,85 \\
Fusarium & 3 & Ituberá, Taperoá & 11,54 \\
Ganoderma & 3 & Ituberá, Una & 11,54 \\
Geotrichum & 1 & Una & 3,85 \\
Lasiodiplodia & 20 & Camamu, Ituberá, Taperoá, Una, Uruçuca \\
Mycoleptodiscus & 1 & Ituberá & 76,92 \\
Pestalotiopsis & 9 & Ituberá, Taperoá, Una & 3,85 \\
Phomopsis & 1 & Una & 34,62 \\
Phytophthora & 4 & Camamu, Ituberá, Una, Uruçuca & 3,85 \\
Rosellinia & 4 & Ituberá, Una & 15,38 \\
Trichoderma & 2 & Ituberá & 15,38 \\
Xylaria & 1 & Una & 7,69 \\
\hline
\end{tabular}

TABELA 2 - Principais diferenças entre as espécies identificadas do gênero Lasiodiplodia patogênicas ao mangostanzeiro.

\begin{tabular}{cccc}
\hline \multirow{2}{*}{ Gênero } & Conídios & \multicolumn{2}{c}{ Colônia } \\
\cline { 2 - 4 } & Tamanho $(\mu \mathrm{m}) *$ & Crescimento & Coloração a $35^{\circ} \mathrm{C}$ \\
\hline L. theobromae & $15-35 \times 10-15$ & Rápido & Cinza-escuro \\
L. parva & $16-23,5 \times 10,5-13$ & + Lento & Rosa-escuro \\
\hline
\end{tabular}

TABELA 3 - Número de secções de caule e raízes de mangostanzeiro inoculadas e infectadas por fungo isolado.

\begin{tabular}{lcccc}
\hline \multirow{2}{*}{ Gênero } & \multicolumn{3}{c|}{ Caule } & \multicolumn{3}{c|}{ Raíz } \\
\cline { 2 - 5 } & $\begin{array}{l}\text { Não infectadas / } \\
\text { inoculadas }\end{array}$ & $\begin{array}{l}\text { Infectadas / } \\
\text { inoculadas }\end{array}$ & $\begin{array}{l}\text { Não infectadas / } \\
\text { inoculadas }\end{array}$ & $\begin{array}{l}\text { Infectadas / } \\
\text { inoculadas }\end{array}$ \\
\hline Lasiodiplodia theobromae & - & $10 / 10$ & - & $10 / 10$ \\
Lasiodiplodia parva & $3 / 10$ & $7 / 10$ & $2 / 10$ & $8 / 10$ \\
Mycoleptodiscus sp. & $9 / 10$ & $1 / 10$ & $8 / 10$ & $2 / 10$ \\
Stilbella sp. & $10 / 10$ & - & $10 / 10$ & - \\
Rhizopus sp. & $10 / 10$ & - & $10 / 10$ & - \\
Testemunha & $10 / 10$ & - & $10 / 10$ & - \\
\hline
\end{tabular}




\begin{tabular}{lccc}
\hline $\begin{array}{l}\text { L. theobromae } \\
\text { L. parva }\end{array}$ & $15-35 \times 10-15$ & Rápido & Cinza-escuro \\
* Média de mais de cinquenta conídios por espécie. & + Lento & Rosa-escuro \\
\hline
\end{tabular}

TABELA 3 - Número de secções de caule e raízes de mangostanzeiro inoculadas e infectadas por fungo isolado.

\begin{tabular}{lccccc}
\hline \multirow{2}{*}{ Gênero } & \multicolumn{3}{c|}{ Caule } & \multicolumn{3}{c}{ Raíz } \\
\cline { 2 - 5 } & $\begin{array}{l}\text { Não infectadas / } \\
\text { inoculadas }\end{array}$ & $\begin{array}{l}\text { Infectadas / } \\
\text { inoculadas }\end{array}$ & $\begin{array}{l}\text { Não infectadas / } \\
\text { inoculadas }\end{array}$ & $\begin{array}{l}\text { Infectadas / } \\
\text { inoculadas }\end{array}$ \\
\hline Lasiodiplodia theobromae & - & $10 / 10$ & - & $10 / 10$ \\
Lasiodiplodia parva & $3 / 10$ & $7 / 10$ & $2 / 10$ & $8 / 10$ \\
Mycoleptodiscus sp. & $9 / 10$ & $1 / 10$ & $8 / 10$ & $2 / 10$ \\
Stilbella sp. & $10 / 10$ & - & $10 / 10$ & - \\
Rhizopus sp. & $10 / 10$ & - & $10 / 10$ & - \\
Testemunha & $10 / 10$ & - & $10 / 10$ & - \\
\hline
\end{tabular}

TABELA 4 - Percentual de frequência de ocorrência (F) dos gêneros isolados.

\begin{tabular}{ccc}
\hline Gênero & \multicolumn{2}{c}{ Resultado } \\
\hline Aspergillus & 4,86 & Esporádico \\
Lasiodiplodia & 83,33 & Muito frequente \\
Mycoleptodiscus & 8,33 & Esporádico \\
Rhizopus & 2,08 & Esporádico \\
Stilbella & 4,17 & Esporádico \\
Trichoderma & 10,42 & Pouco frequente \\
\hline
\end{tabular}

TABELA 5 - Percentual de constância (C) dos gêneros isolados.

\begin{tabular}{lcc}
\hline \multicolumn{1}{c}{ Gênero } & \multicolumn{2}{c}{ Resultado } \\
\hline Aspergillus & 66,67 & Constante \\
Lasiodiplodia & 100,00 & Constante \\
Mycoleptodiscus & 16,67 & Acidental \\
Rhizopus & 16,67 & Acidental \\
Stilbella & 33,33 & Acessória \\
Trichoderma & 50,00 & Acessória \\
\hline
\end{tabular}



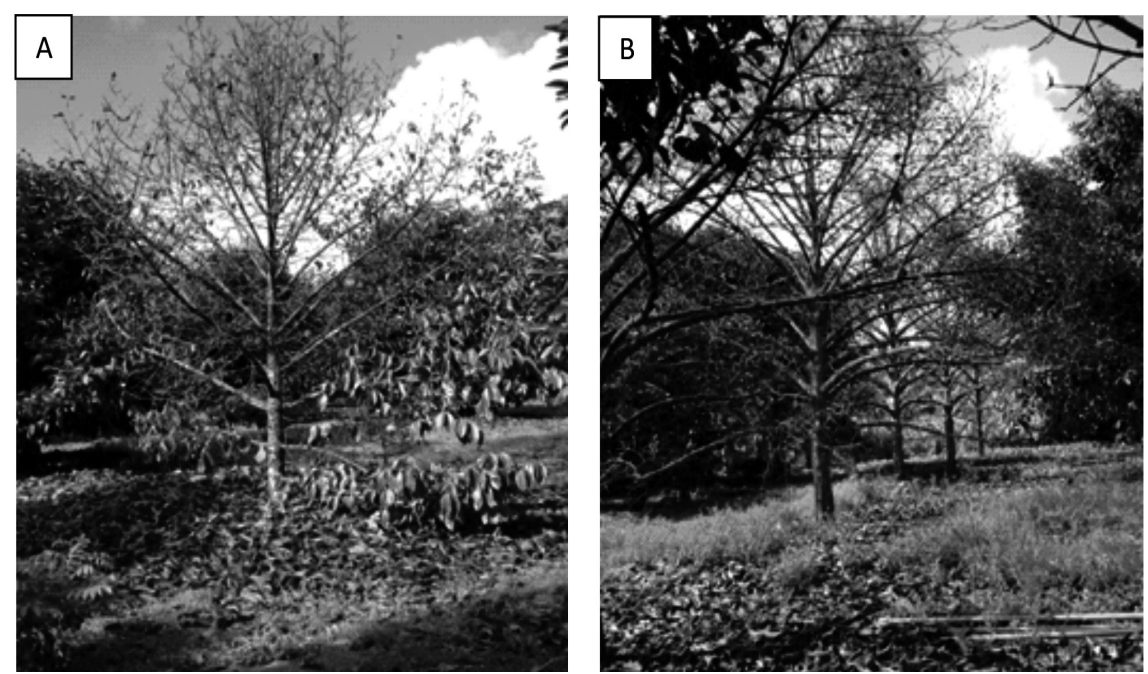

FIGURA 1 - Mangostanzeiros com sintomas de declínio na região sul da Bahia. A) Planta isolada; B) Plantas em fileira.
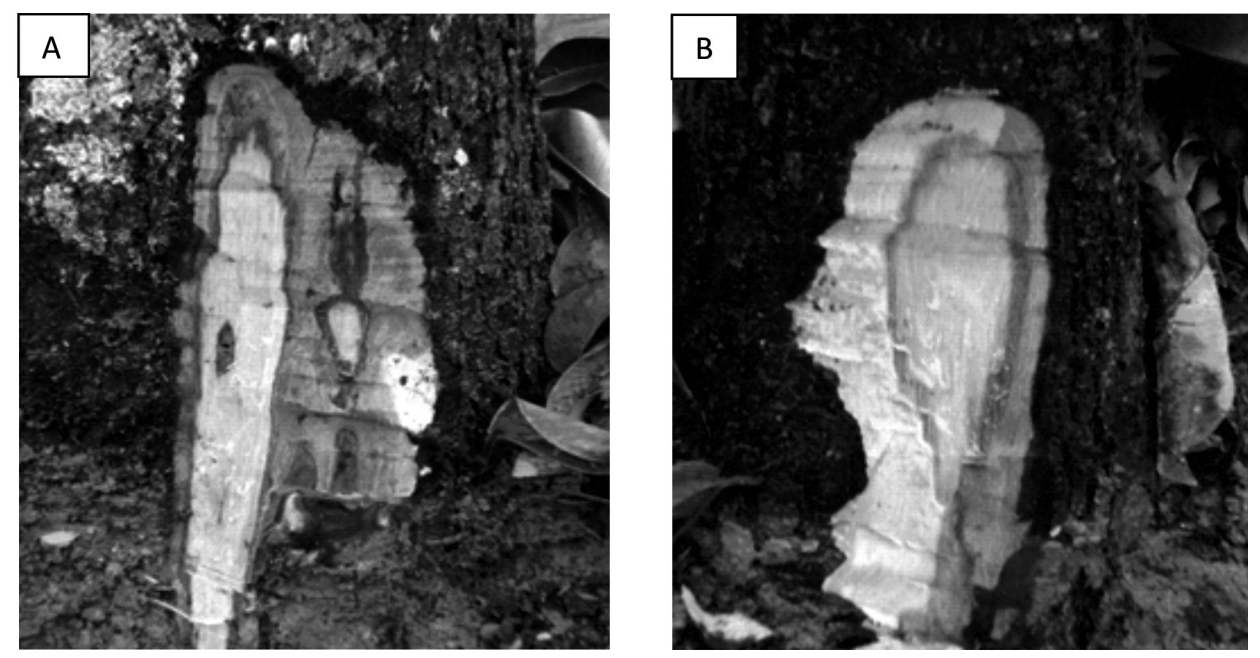

FIGURA 2 - A) Perfurações feitas por escolitídeos (Coleoptera: Scolytidae) em um tronco com tecidos necrosados; B) Detalhe da lesão, área de transição entre o tecido doente e o sadio. 

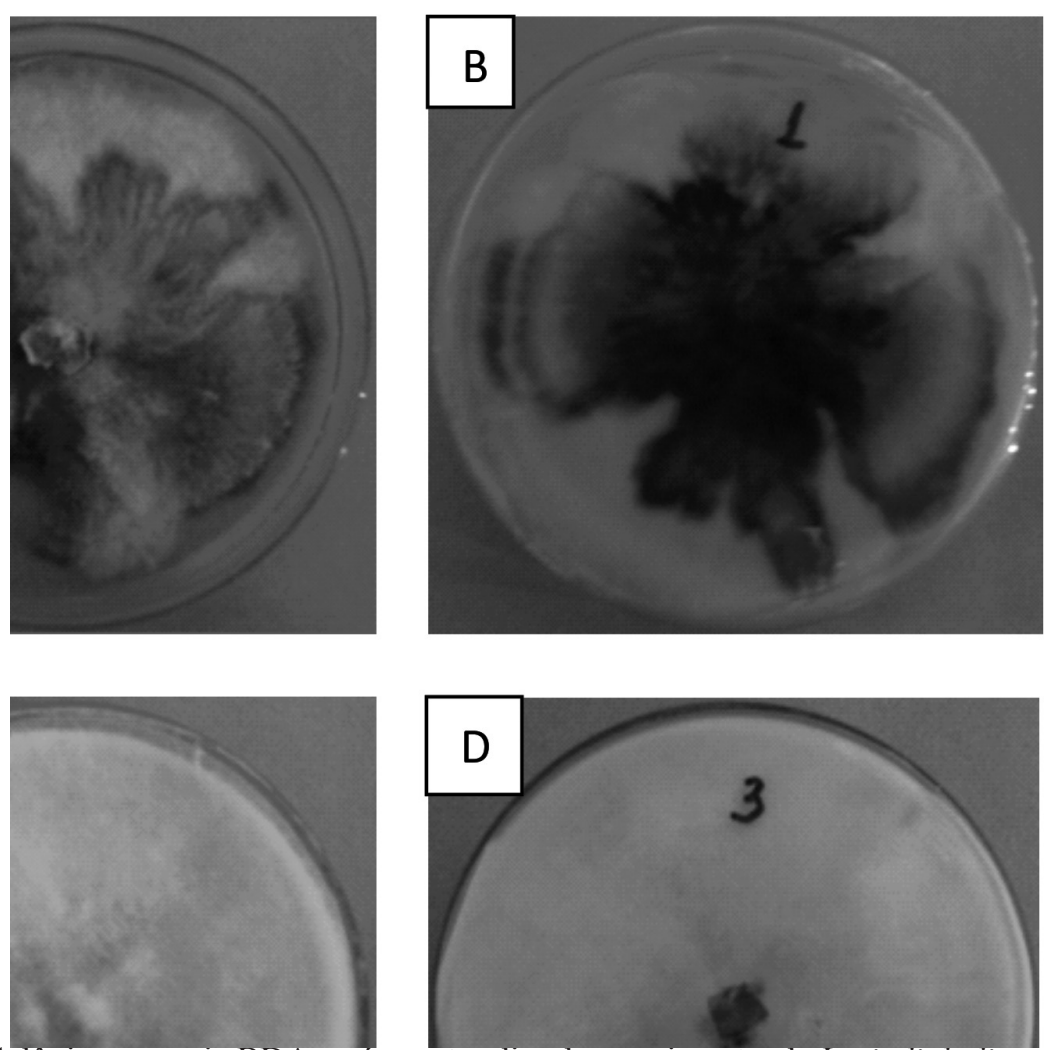

FIGURA 3 - Colônias em meio BDA, após quatro dias de crescimento, de Lasiodiplodia parva A) anverso; B) reverso e de Lasiodiplodia theobromae; C) anverso; D) reverso.
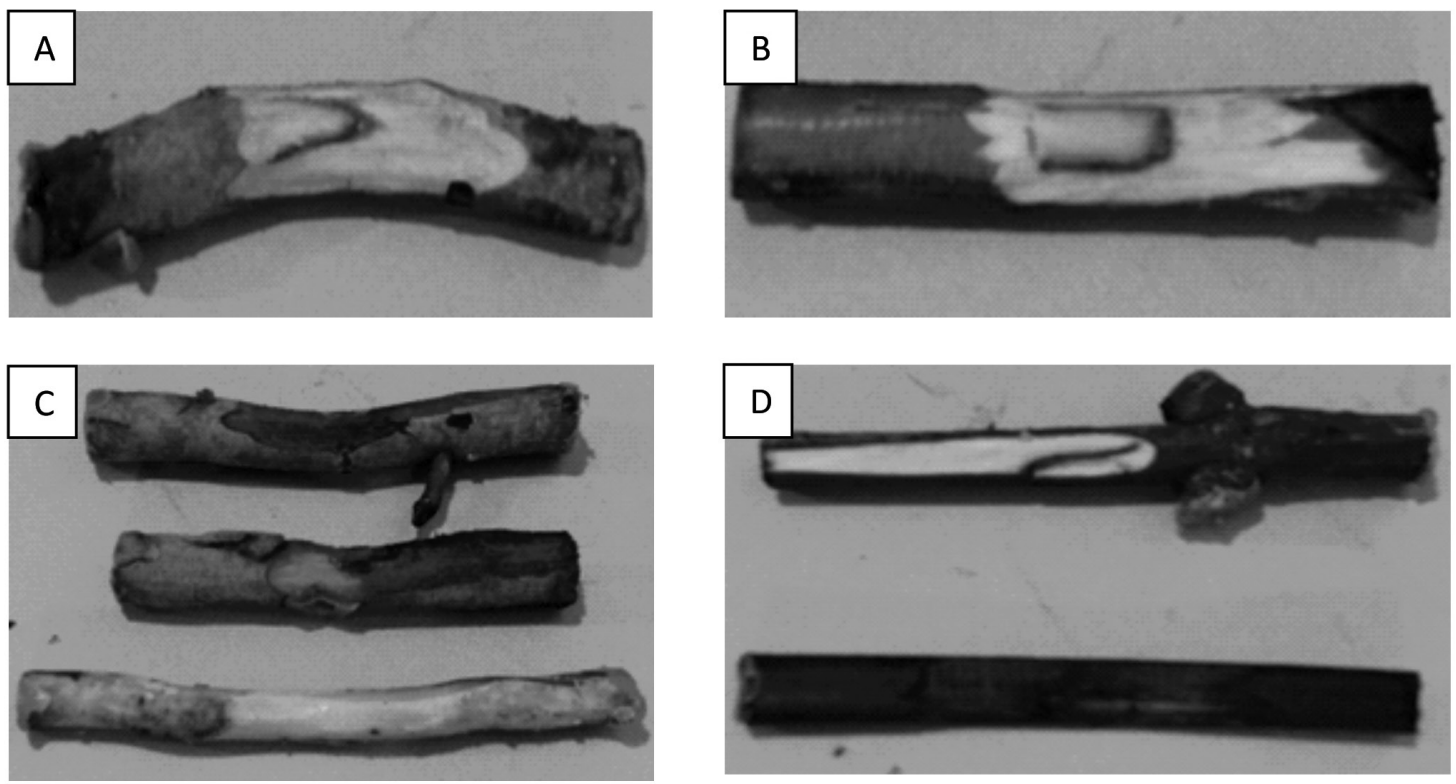

FIGURA 4 - Secções de raiz e caule de mangostanzeiros com sintomas e testemunhas. A) Secção de raiz sadia sem infecção; B) Secção de caule sadio sem infecção; C) Secções de raízes infectadas com Lasiodiplodia theobromae (superior), L. parva (intermediária) e sadia (inferior); D) Secções de caule sadio (superior) e infectado com L. theobromae (inferior). 

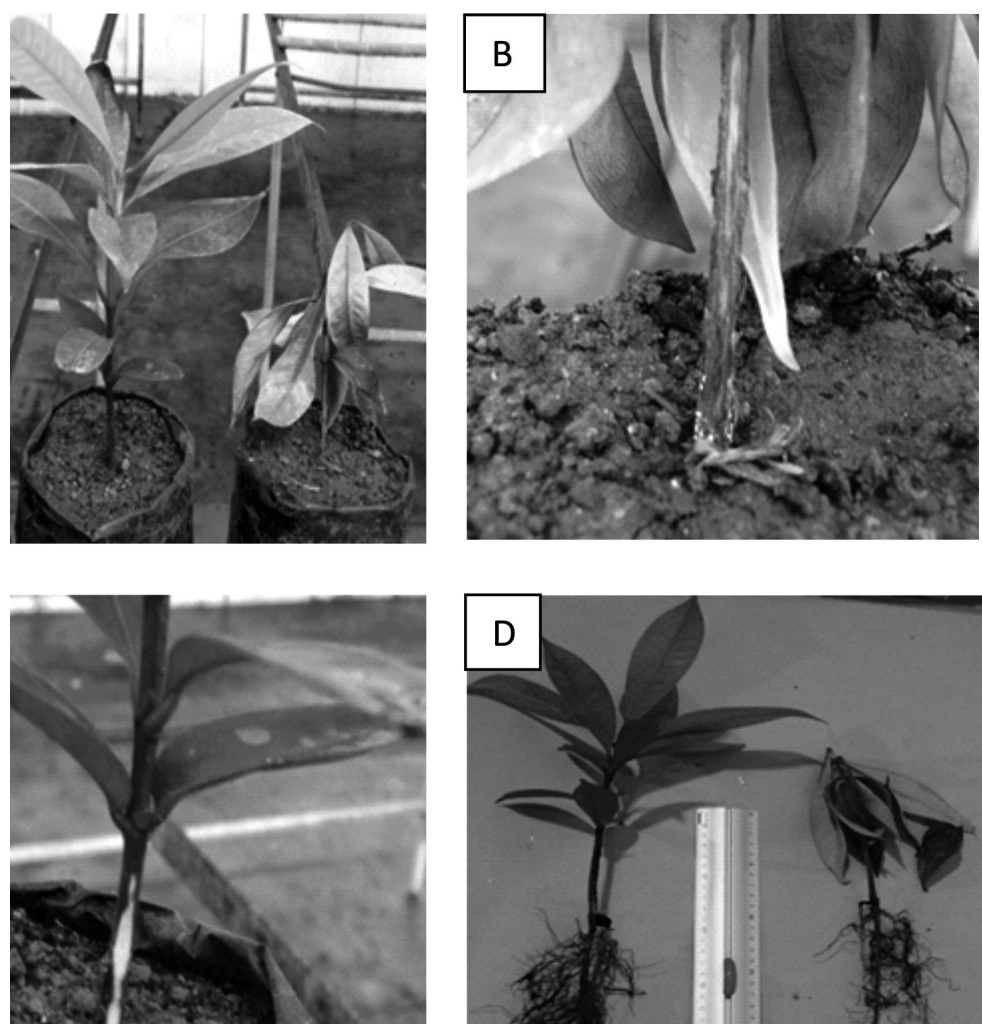

FIGURA 5 - Sintomas em mudas de mangostanzeiros inoculadas. A) Testemunha entre duas plantas infectadas por Lasiodiplodia parva a esquerda e L. theobromae à direita; B) Lesão extensa decorrente da infecção provocada por L. theobromae; C) Planta-testemunha sem infecção; D) Sistema radicular de muda sadia (esquerda) e infectada por L. parva (direita).

\section{CONCLUSÕES}

1-Observou-se associação constante de Lasiodiplodia theobromae e L. parva com os sintomas de declínio em mangostanzeiros com mais de cinco anos após o plantio no campo.

2-Os fungos L. theobromae e L. parva induziram sintomas de declínio e morte em mudas de mangostanzeiros em condições de casa de vegetação e lesões necróticas em secções vivas de ramos e de raízes em condições de laboratório, sendo comprovadamente os agentes causais do declínio de mangostanzeiros.

4-As espécies $L$. theobromae e $L$. parva foram isoladas em todas as coletas realizadas.

5-Lasiodiplodia parva e Rosellinia sp. são novos registros para mangostanzeiro.

\section{REFERÊNCIAS}

AlveS, A.; CROUS, P.W.; CORREIA, A.; PHILLIPS, A.J.L. Morphological and molecular data reveal cryptic speciation in Lasiodiplodia theobromae. Fungal Diversity, Yunnan, v. 28, p. $1-13,2008$.

BEZERRA, J.L.; SACRAMENTO, C.K.;ALMEIDA, O.C.; BEZERRA, K.M.T. Ocorrência de murcha do mangostãozeiro (Garcinia mangostana L.) na região sul da Bahia In: SEMINÁRIO DE PESQUISA E PÓS-GRADUAÇÃO DA UESC, 7., 2003, Ilhéus. Anais... Ilhéus: UESC, 2003. p.117-118.

CARDOSO, J.E.; BEZERRA, M.A.; VIANA, F.M.P.; SOUSA, T.R.M. de.; CYSNE, A.Q.; FARIAS, F.C. Ocorrência endofítica de Lasiodiplodia theobromae em tecidos de cajueiro e sua transmissão por propágulos. Summa Phytopathologica, Botucatu, v. 35, n. $4,2009$. 
CAVALCANTI, L.H.; MOBIN, M. Myxomycetes associated with palm trees at the Sete Cidades National Park, Piauí, Piauí State, Brazil. Systematics and Geography of Plants, Norway, v. 74, n. 1, p. 109-127, 2004.

DAJOZ, R. Ecologia geral. Petrópolis: Ed. Vozes, 1983. 472p.

FUKUDA, Y.; HIROOKA, Y.; ONO, T.; KOBAYASHI, T.; NATSUAKI, K.T. Lasiodiplodia pod rot of Theobroma cacao L. caused by Lasiodiplodia theobromae. Journal of Agriculture Science, Tokyo v. 53, n. 2, p. 130-138, 2008.

ITO, M.A.; PARADELA FILHO, O.; ITO, M.F.; TEIXEIRA, E.P. Ocorrência de Botryospharia dothidea em macadâmia. Fitopatologia Brasileira, Brasília, v. 26, p. 397, ago. 2001. Suplemento.

LINS, S.R.; ALVES, E.; OLIVEIRA, S.M.A. Estudos da interação Lasiodiplodia theobromae $\mathrm{x}$ mangueira e caracterização morfológica de isolados do patógeno. Acta Microscópica, Rio de Janeiro, v. 19, n. 3. P. 221-231, 2010.

LUZ, E.D.M.N. The roles of five species of Phytophthora in infection and disease of roots, stems, and pods of Theobroma cacao L. 1989. PhD (Thesis) - University of Florida, Gainesville, 1989.
LUZ, E.D.M.N.; SILVA, S.D.V.M. Podridão-parda dos frutos, cancro e outras doenças causadas por Phytophthora no cacaueiro. In: LUZ, E.D.M.N. et al. (Org). Doenças causadas por Phytophthora no Brasil. Campinas: Livraria Editora Rural, 2001. v. 1, p. 175-265.

MARTIJN TEN HOOPEN, G.; KRAUSS, U. Biology and control of Rosellinia bunodes, Rosellinia necatrix and Rosellinia pepo: a review. Crop Protection, Guildford, v. 25, p. 89-107, 2006.

OLIVEIRA, M.L. de; LUZ, E.D.M.N. Identificação e manejo das principais doenças do cacaueiro no Brasil. Ilhéus: CEPLAC/CEPEC/SEFIT, 2005. $132 \mathrm{p}$.

PEREIRA, O.L.; DUTRA, D.S.; DIAS, L.A.S. Lasiodiplodia theobromae is the causal agente of a damaging root and collar rot disease on the biofuel plant Jatropha curcas in Brazil. Australasian Plant Disease Notes, Sydney, v. 4, p. 120-123, 2009.

SACRAMENTO, C.K.; COELHO JR, E.; MULLER, C.H.; CARVALHO, J.E.U.; NASCIMENTO, W.M.O., Cultivo de mangostão no Brasil. Revista Brasileira de Fruticultura, Jaboticabal, v. 29, p. 197-206, 2007. 